\title{
Potential impacts of projected climate change on safe carrying capacities for extensive grazing lands of northern Australia
}

\author{
$\underline{\text { J.C. Scanlan }}^{\text {a }}$, R.A. Cowley ${ }^{\text {b }}$ L.I. Pahl ${ }^{\text {a }}$, G.L. Whish ${ }^{\text {a }}$ and N.D. MacLeod ${ }^{c}$ \\ ${ }^{a}$ Department of Employment Economic Development and Innovation, P.O. Box 102, Toowoomba, Qld. 4350 \\ ${ }^{b}$ Department of Resources,' Darwin, NT 0851 \\ ${ }^{c}$ CSIRO Ecosystem Sciences, Dutton Park, Qld 4102. \\ Email:joe.scanlan@deedi.qld.gov.au
}

\begin{abstract}
Climate change has the potential to significantly affect the productivity of the extensive grazing lands of northern Australia. One area that may be impacted is the estimated safe carrying capacity of grazed pastures. This is being examined within the Northern Grazing Systems program being coordinated by Meat and Livestock Australia. Here we report the potential impact of different climate scenarios on the safe carrying capacities of grazing lands using the GRASP pasture simulation model.

GRASP has previously been used to investigate many aspects of grazing land management, from estimating 'safe' carrying capacities through to impacts of projected climate change. The model has been adapted to more realistically represent the process of pasture degradation. Additionally, growth parameters were modified to represent the effects of elevated $\mathrm{CO}_{2}$. These changes are described.

The updated model has been used to estimate impacts of projected climate change on pasture condition, soil loss and animal production for a range of land types and locations across northern Australia. Initial simulations were undertaken for the Maranoa and Fitzroy regions of Queensland and the Victoria River District of the northern Territory.

The working definition employed for a 'safe' carrying capacity is the fixed stocking rate that would maintain good pasture condition (at least 70\% perennials average) over a 30-50 year period. The simulation runs are based on current climate and two possible 'future climates' selected from 392 files per region provided by the Queensland Climate Change Centre of Excellence. Mean values of temperatures and rainfall for all files were compared with the current climate file, and ranked in terms of change in temperature and change in rainfall. The selected files represented (1) $3^{\circ} \mathrm{C}$ increase with decile 9 rainfall; (2) $3^{\circ} \mathrm{C}$ increase with decile 1 rainfall. These represented upper and lower limits of the degree of change in rainfall at a temperature increase that is plausible by 2050 .

For nitrogen-limited land types, estimated safe carrying capacities actually improved or experienced no change for the two future climates. By contrast, the safe carrying capacities for some other land types decreased by more than $50 \%$, especially under the $3^{\circ} \mathrm{C}$ increase in temperature with decile 1 rainfall. Pasture production responses tended to be proportionally greater than the projected changes in rainfall, as were carrying capacities but to an even greater extent.
\end{abstract}

Some reasons for the variable responses and implications for the extensive grazing industries are discussed.

Keywords: climate change, safe carrying capacity, extensive grazing lands 


\section{INTRODUCTION}

Some potential impacts of climate change on the extensive grazing lands of northern Australia have been highlighted by McKeon et al. (2009). Identified gaps for further work were the effects of enhanced $\mathrm{CO}_{2}$ on forage production and the effects of climate change on long-term carrying capacities of pastures. Considerable uncertainty remains about the direction and magnitude of changes in rainfall in northern Australia, although the range of possible changes has been defined (data provided by the Consistent Climate Scenario Project, undertaken by Queensland Climate Change Centre of Excellence (QCCCE) and funded by the Commonwealth Department of Agriculture, Fisheries and Forestry Australia's Farming Future - Climate Change Research Program). Webb et al. (2011) have examined some of the responses of pastures for a range of climate projections showing differences among land types for different response variables (e.g. pasture growth, soil loss). Such preliminary analyses are necessary to examine the range of possible impacts to enable land managers and government agencies to consider what adaptation actions should be considered.

From 2009, Meat and Livestock Australia (MLA) has supported the Northern Grazing Systems (NGS) project that is being undertaken by CSIRO, and Queensland, Northern Territory and Western Australian agencies involved in grazing management activities. The ramifications of the potential impacts of climate change for current management practices relating to stocking rate, pasture resting and use of prescribed fire were identified as important topics of research for the NGS project.

The results presented here builds upon the work of McKeon et al. (2009) by using new climate change projections and a modified approach to determining 'safe' carrying capacity. Simulations of the response of different land types in the Northern Territory and Queensland were undertaken to investigate the impacts of selected climate projections on pasture growth and 'safe' carrying capacities.

\section{METHOD}

The GRASP pasture simulation model has been widely used to examine many aspects of pasture management in northern Australia (e.g. Rickert et al. 2000; McKeon et al. 2009). The model has been recently modified to enable certain aspects of grazing management to be simulated in a more realistic manner (see Scanlan et al. 2011, this volume). To represent the effects of elevated $\mathrm{CO}_{2}$, a number of parameters within the GRASP model were adjusted (C.S. Stokes and G.M. McKeon, pers. comm.) based on recent experimental data (Stokes et al. 2005) and a review of other experiments.

Two land types from the Victoria River District (VRD) in the Northern Territory and two from the Fitzroy region of central Queensland were selected to study the potential impacts of selected climate projections. The black cracking clay (VRD) and brigalow/blackbutt land types (Fitzroy) are highly productive land types (Whish 2011), with average annual pasture production in excess of $3000 \mathrm{~kg} / \mathrm{ha}$ (Table 1). By contrast, the Humbert (VRD) and narrowleaf ironbark land types (Fitzroy) are much less productive at around $1400 \mathrm{~kg} / \mathrm{ha}$ and $2100 \mathrm{~kg} /$ ha respectively.

A number of definitions exist of 'safe' carrying capacity. Scanlan et al. (2010) developed a method using the GRASP model to simulate the percentage perennials in pastures over a 30-year period as the fixed stocking rate increased. This was done by running the GRASP model for a particular combination of land type and climate projection many times with the fixed stocking rate progressively increasing in each run. The model outputs presented here are mean pasture production and mean percent perennials over the 30 -year simulation period, and estimated safe carrying capacities. Safe carrying capacity (for the period simulated) is the fixed stocking rate that maintained the desired pasture condition throughout the simulation period, presented as adult equivalents (AE) per $100 \mathrm{ha}$ (an $\mathrm{AE}$ is a $450 \mathrm{~kg}$ steer). For pastures that are initially in good condition, 'desired percentage perennials' is $80 \%$ although other values have been used (e.g. $70 \%$ in Scanlan et al. 2010); for pastures in poor condition, the safe carrying capacity is that which allowed some improvement in condition or at least no further deterioration.

The selection of climate files followed that used by Webb et al. (2011) and the same approach was used by Pahl et al. (2011, this volume). Projected climate data were provided by the QCCCE Consistent Climate Scenarios Project funded by the Commonwealth Department of Agriculture, Forestry and Fisheries. For each location, we obtained 392 projected climate files, each representing a particular combination of global circulation model, $\mathrm{CO}_{2}$ emissions scenario, sensitivity to $\mathrm{CO}_{2}$ and date. From this wide array of projected climate files available, two were selected. Initial selection was for all files that gave an increase in temperature of approximately $3^{\circ} \mathrm{C}$. For those files, we ranked them in order of increasing negative impact on rainfall and selected two files - one having decile 9 rainfall and the other decile 1 rainfall. 
Table 1. Mean climate parameters for baseline and projected climate files used in simulations of land types in the VRD of Northern Territory and the Fitzroy region of Central Queensland.

\begin{tabular}{|c|c|c|c|c|c|c|}
\hline Simulations - VRD & Code & $\begin{array}{l}\text { Annual } \\
\text { rainfall } \\
(\mathrm{mm})\end{array}$ & $\begin{array}{c}\text { Mean annual } \\
\text { temperature } \\
\left({ }^{\circ} \mathrm{C}\right)\end{array}$ & $\begin{array}{c}\text { Pan } \\
\text { evaporation } \\
(\mathrm{mm} / \text { day })\end{array}$ & $\begin{array}{l}\text { Radiation } \\
\left(\mathrm{MJ} / \mathrm{m}^{2}\right. \\
\text { /day })\end{array}$ & $\begin{array}{c}\text { Vapour } \\
\text { pressure } \\
\text { deficit } \\
(\mathrm{kPa})\end{array}$ \\
\hline 1 Current rainfall and $\mathrm{CO}_{2}$ & Base & 624 & 26.4 & 7.67 & 21.6 & 16.8 \\
\hline $\begin{array}{l}2 \text { Increase temperature } \\
\text { with decile } 9 \text { rainfall at } \\
\sim 540 \text { ppm } \mathrm{CO}_{2}\end{array}$ & $\begin{array}{l}+3^{\circ} \mathrm{C} \\
\text { Dec } 9 \mathrm{R}\end{array}$ & 802 & 28.8 & 8.00 & 22.1 & 17.9 \\
\hline $\begin{array}{l}3 \text { Increase temperature } \\
\text { with decile } 1 \text { rainfall } \sim 540 \\
\text { ppm } \mathrm{CO}_{2}\end{array}$ & $\begin{array}{l}+3^{\circ} \mathrm{C} \\
\text { Dec } 1 \mathrm{R}\end{array}$ & 620 & 29.1 & 8.41 & 21.3 & 19.4 \\
\hline \multicolumn{7}{|l|}{ Simulations - Fitzroy } \\
\hline 1 Current rainfall and $\mathrm{CO}_{2}$ & Base & 711 & 22.2 & 5.46 & 19.9 & 18.4 \\
\hline $\begin{array}{l}2 \text { Increase temperature } \\
\text { with decile } 9 \text { rainfall } \sim 540 \\
\text { ppm } \mathrm{CO}_{2}\end{array}$ & $\begin{array}{l}+3^{\circ} \mathrm{C} \\
\text { Dec } 9 \mathrm{R}\end{array}$ & 684 & 24.6 & 5.95 & 19.8 & 21.4 \\
\hline $\begin{array}{l}3 \text { Increase temperature } \\
\text { with decile } 1 \text { rainfall } \sim 540 \\
\text { ppm } \mathrm{CO}_{2}\end{array}$ & $\begin{array}{l}+3^{\circ} \mathrm{C} \\
\text { Dec } 1 \mathrm{R}\end{array}$ & 503 & 25.1 & 5.85 & 20.0 & 21.4 \\
\hline
\end{tabular}

\section{RESULTS}

\subsection{Overview}

Simulated pasture production under current and projected climates is shown in Table 2. The enhanced $\mathrm{CO}_{2}$ under current climate led to increased mean pasture growth in all land types (data not shown). These production results are similar to those produced under the projected climate data using the decile 9 rainfall. By contrast, estimated growth using decile 1 climate file rainfall was lower than for current climate and current $\mathrm{CO}_{2}$ levels, except for the brigalow/blackbutt land type.

Table 2. Mean pasture production $(\mathrm{kg} / \mathrm{ha} / \mathrm{yr})$ for three simulations for land types in the VRD and Fitzroy region during 1980-2010.

\begin{tabular}{|c|c|c|c|c|}
\hline Simulations & $\begin{array}{l}\text { VRD- Black } \\
\text { cracking clay }\end{array}$ & $\begin{array}{l}\text { VRD - } \\
\text { Humbert }\end{array}$ & $\begin{array}{c}\text { Fitzroy - } \\
\text { Brigalow / } \\
\text { blackbutt }\end{array}$ & $\begin{array}{l}\text { Fitzroy -Narrow- } \\
\text { leaved ironbark }\end{array}$ \\
\hline 1. Current rainfall and $\mathrm{CO}_{2}$ & 3196 & 1350 & 3667 & 2077 \\
\hline $\begin{array}{l}\text { 2. Increase temperature with } \\
\text { decile } 9 \text { rainfall } \sim 540 \mathrm{ppm} \mathrm{CO}_{2}\end{array}$ & 3640 & 1488 & 3948 & 2209 \\
\hline $\begin{array}{l}\text { 3. Increase temperature with } \\
\text { decile } 1 \text { rainfall } \sim 540 \mathrm{ppm} \mathrm{CO}_{2}\end{array}$ & 2818 & 1083 & 3857 & 1951 \\
\hline
\end{tabular}

For all simulations, the simulated percent perennials remained at the maximum $(90 \%)$ up to a threshold stocking rate, above which the percent perennials decreased (Figure 1). Under current climate conditions, this threshold for the Humbert land type in the VRD was $\sim 2 \mathrm{AE} / 100$ ha while at the other extreme, it was 32 $\mathrm{AE} / 100$ ha for brigalow/blackbutt in Fitzroy. At stocking rates lower than these threshold values, utilisation rates were sufficiently low that pasture condition remained excellent. This reflected the different productivities of the land types. Once the threshold was exceeded, the percent perennials decreased quickly as stocking rate increased further. This resulted from an initial decline in pasture condition during the simulation period which then led to decreased pasture production. Because stocking rate was held constant and the pasture production is reduced, utilisation necessarily increases with a further reduction in pasture 
condition; eventually leading to a significant decline in condition and limited pasture growth. At some high stocking rate, the percent perennials reached a relatively stable lower value. For all land types, that lower limit was around $10 \%$ perennials. This asymptote results from presenting the mean percent perennials for simulations commencing at $90 \%$ perennials, with a rapid decline to the minimum possible (1\%) over the first 12 years of the 30 -year simulation period. For the sake of presentation, graphs in Figure 1 were truncated before all land types and region combinations reached this figure.

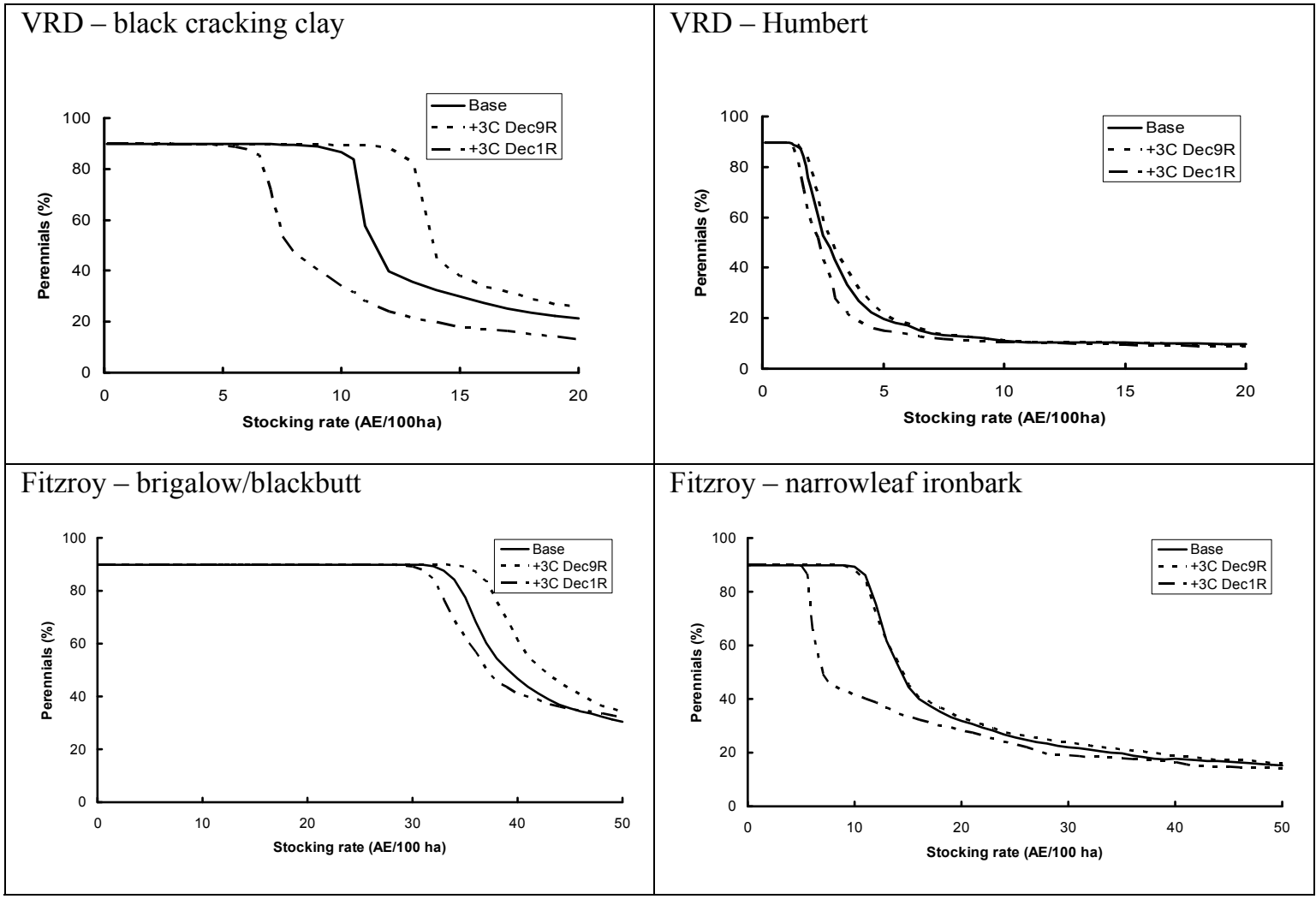

Figure 1. Mean percent perennials over the simulation period (1980-2010) in selected land types in the VRD and Fitzroy region for a range of stocking rates.

The effects of changing climate on rainfall, pasture growth and safe carrying capacities can be seen in Figure 2. In the VRD under decile 9 rainfall scenario, pasture growth increased by a smaller percentage than rainfall; safe carrying capacity increased by a greater percentage than either rainfall or pasture growth. For decile 1 rainfall scenario, safe carrying capacity in fertile conditions was reduced to a greater extent than expected based on rainfall alone; the reduction in poorer land types was not as large as expected based on the reduction in rainfall.

In the Fitzroy region, safe carrying capacity for decile 9 rainfall scenarios is similar to or slightly greater than under current conditions, despite a small reduction in rainfall. Under decile 1 rainfall scenario, the reduction in pasture growth is less than the reduction in rainfall relative to current conditions. For the fertile site, safe carrying capacity is not reduced as much as rainfall, but for the less fertile site, the impact on safe carrying capacity is greater than the reduction in rainfall.

For very infertile land types, where annual growth is limited by nitrogen availability in most years, the increased growth rate due to elevated $\mathrm{CO}_{2}$ more than compensated for the reduced rainfall, and thus pasture growth increased, even under decile 1 conditions (data not shown). In both locations, the mean change in pasture growth is not a good predictor of the change in safe carrying capacity. 


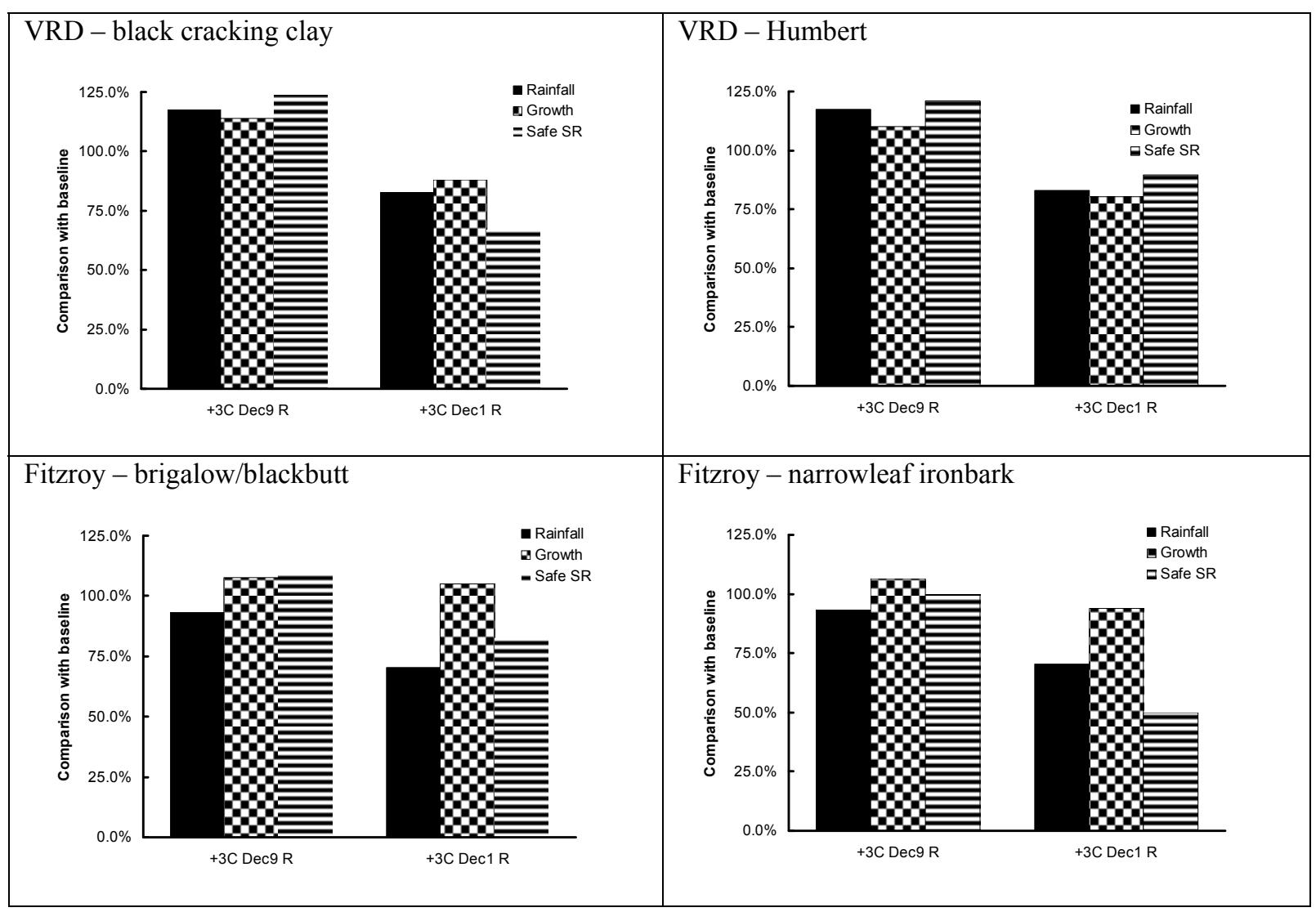

Figure 2. Relative changes in rainfall, pasture growth and safe carrying capacity for land types in the VRD and Fitzroy region compared with the baseline of current conditions.

\section{DISCUSSION}

There is not a direct, fixed relationship between simulated change in pasture production due to climate change and the associated change in estimated safe carrying capacity (using the definition in this paper). The assumption of a fixed relationship between pasture production and safe carrying capacity has been used under current climatic conditions to estimate carrying capacities for a variety of land types (e.g. by Johnston et al. 1996; Day et al. 1997). However, this approach should be used with caution when assessing the likely impact of climate change. Land types will differ in their responses to climate change, and the direction and magnitude of change will also differ between the climate change projections being evaluated.

Some preliminary patterns are suggested for the regions studied here. If rainfall increases in fertile land types, the combination of higher rainfall and higher growth parameters due to elevated $\mathrm{CO}_{2}$ may increase safe carrying capacity (assuming current pasture and stock management practices remain the same). The safe carrying capacity may increase for these fertile land types even if the rainfall declines by a small percentage. In moderately fertile land types, the counteracting influences of small decreases in rainfall and enhanced growth parameters due to elevated $\mathrm{CO}_{2}$ may result in little or no net effect. For poor land types, moderate reductions in rainfall may have little negative effect on safe carrying capacity. A major proviso is that the reduced nitrogen concentration in pasture growth under elevated $\mathrm{CO}_{2}$ conditions (Stokes et al. 2005) does not directly influence the carrying capacity and that the only influence is due to changes in pasture production.

There is likely to be substantial variation between different regions across northern Australia in the response to climate change. In part this is due to differences in the climate projections, with some regions less likely to experience decreases in rainfall than others. When this is combined with the differences between land types mentioned above, generalisations are fraught with danger. The approach used by Webb et al. (2011) is to evaluate the range of possible outcomes (between the $10^{\text {th }}$ and $90^{\text {th }}$ percentile of climate change predictions). Any suggested adaptation measures should be robust enough to cope with a range of possible future climates; attempting to optimise adaptation measures for the median effect could possibly be maladaptive if the actual climate that is experienced is substantially different from the median. 
A number of factors not examined in this study are likely to have an impact on safe carrying capacity under climate change. The first is that the 'change factor approach' used to develop future climate projections used in this study does not result in different numbers of rain days per year: changes in rainfall are calculated by applying a multiplier to the existing rainfall patterns. In the current runoff-soil loss model in GRASP (based on Scanlan et al. 1996), rainfall intensity is an important factor in estimating runoff and its estimation is based on the magnitude of daily rainfall. A new method developed by G. Fraser (pers. comm.) could overcome this limitation.

Another relevant factor over much of northern Australia is the presence of trees in many land types. Webb et al. (2011) have reported considerable impacts of climate change and trees on pasture growth in some land types. It is likely that these production impacts will influence safe carrying capacities. However, it cannot be assumed that the changes in safe carrying capacity will follow the same pattern as change in pasture production, as shown by this study.

Much more work will be required to evaluate the interactions of climate change and the important characteristics of land types across northern Australia. Results from such work will inform the adaptation measures developed to cope with the potential adverse effects and the potential opportunities brought about by climate change. It is clear that simulation modelling using tools such as GRASP has a critical role to play in investigating adaptation strategies and the potential impacts of climate change on Australia's northern cattle industry.

\section{ACKNOWLEDGMENTS}

The authors acknowledge Drs Rodd Dyer, Mick Quirk and Wayne Hall for their guidance throughout this continuing work and Meat and Livestock Australia for their development and funding of the Northern Grazing System project. Additional funds were received through the Australian Department of Agriculture, Fisheries and Forestry's Caring for Our Country and Australia's Farming Future: Climate Change Research programs. Dr Greg McKeon has provided insights and encouragement during this work.

\section{REFERENCES}

Day, K.A., W.J. Scattini, and J.C. Osborne. (1997). Extending carrying capacity calculations to the central Burnett region of Queensland. In: 'DroughtPlan - Building on Grazier Participation to Manage for Climate Variability. Climate Variability Series, Occasional Paper CV01'. pp. 112-119. (Land and Water Resources Research and Development Corporation: Canberra.)

Johnston, P.W., G.M. McKeon, and K.A. Day. (1996). Objective 'safe' grazing capacities for south-west Queensland Australia: development of a model for individual properties. Rangeland Journal 18, 244258.

McKeon, G.M., A.J. Ash, W.B. Hall, and M. Stafford-Smith. (2000). Simulation of grazing strategies for beef production in north-east Queensland. In Applications of seasonal climate forecasting in agricultural and natural systems-The Australian experience. (Eds. G. Hammer, N. Nichols and C. Mitchell.) pp. 22752. Kluwer Academic Press, Netherlands.

McKeon, G.M., G.S. Stone, J.I. Syktus, J.O. Carter, N.R. Flood, D.G. Ahrens, D. N., Bruget, C.R. Chilcott, D.H. Cobon, R.A. Cowley, S.J. Crimp, G.W. Fraser, S.M. Howden, P.W. Johnston, J.G. Ryan, C.J. Stokes, and K.A. Day. (2009). Climate change impacts on northern Australian rangeland livestock carrying capacity: a review of issues. Rangeland Journal. 31: 1-29

Pahl, L.I., G.L. Whish, N.D. MacLeod, J.C. Scanlan, and R.A. Cowley. (2011). Improved pasture management can improve profitability and resilience to climate change in northern Australia. MODSIM 2011

Rickert, K.G., J.W. Stuth, and G.M. McKeon. (2000). Modelling pasture and animal production. In: Field and Laboratory Methods for grassland and Animal Production Research (eds. L. 't Mannetje and R.M. Jones). (CAB International Publishing: New York).

Scanlan, J.C., A.J. Pressland, and D.J. Myles. (1996). Run-off and soil movement on mid-slopes in north-east Queensland grazed woodlands. Rangeland Journal 18 33-46.

Scanlan, J.C., G.L. Whish, L.I. Pahl, R.A. Cowley, and N.D. MacLeod. (2010). The Northern Grazing Systems project: estimating safe stocking rate. Australian Rangeland Conference, Bourke 2010.

Scanlan, J.C., G.L. Whish, L.I. Pahl, R.A. Cowley, and N.D. MacLeod. (2011). Assessing the impact of pasture resting on pasture condition in the extensive grazing lands of northern Australia. MODSIM 2011

Stokes, C. J., A.J. Ash, M. Tibbett, and J.A.M. Holtum. (2005). OzFACE: the Australian Savanna Free Air $\mathrm{CO}_{2}$ Enrichment facility and its relevance to carbon cycling issues in a tropical savanna. Australian Journal of Botany 53, 677-687. 
Scanlan et al., Potential impacts of projected climate change on safe carrying capacity

Webb, N.P., C.J. Stokes, and J.C. Scanlan. (2011). Interacting effects of vegetation, soils and management on the sensitivity of savanna rangelands to climate change. (Climatic Change accepted)

Whish, G.L. (2011). Land types of Queensland. Version 2.0. Prepared by the Grazing Land Management Workshop Team, PR07-3212, Department of Employment, Economic Development and Innovation, Brisbane. 